\title{
ON A MULTI-WAVE ELASTODYNAMICAL QUADRILATERAL INFINITE ELEMENT FOR SOIL STRUCTURE INTERACTION
}

\section{O MULTIVALNOM ELASTODINAMIČKOM KVADRILATERALNOM BESKONAČNOM ELEMENTU ZA OBUHVATANJE INTERAKCIJE KONSTRUKCIJE I TLA}

\author{
Konstantin S KAZAKOV
}

\author{
ORIGINALNI NAUČNI RAD \\ ORIGINAL SCIENTIFIC PAPER \\ UDK:624.131.5
}

doi:10.5937/GRMK2001003K

\section{INTRODUCTION}

This section is devoted to review the historical background of infinite elements from the original works to the latest contribution. Exterior domain scattering problems appear naturally in many engineering fields such as electrodynamics, magnetic problems, fluid flow, thermal analyses and so on. Wave propagation in an elastic infinite media and scattering of waves on bodies in a fluid which extends infinitely are of particular interest. When numerical methods are used the main difficulty in such problems arises in unbounded domain that has to be discretizied. Many suggestions and ideas for the treatment of the exterior domain have been presented and discussed in a number of research papers over the period of three decades. The exterior (infinite) domain cannot be completely discretizied with standard finite elements, and a lot of efforts have been spent in the development of new infinite element techniques.

One possible approach is to just truncate the computational domain at some distance away and to impose "appropriate" boundary conditions. Such boundary is called "artificial" boundary. In this case socalled viscous, absorbing or transmitting boundary conditions can also be used. It is evident that the computational efficiency depends than on the localization of the "artificial" boundary and the type of the boundary conditions. In a lot of problems such techniques provide acceptable results. In Soil-Structure Interaction problems such techniques are known as Substructural approach.

Konstantin S. Kazakov, Associate Professor Dr. Department of Structural Mechanics, VSU "Luben Karavelov", Sofia

\section{INFINITE ELEMENT METHOD WORKS}

Infinite element method was introduced about three decades ago in the original work of Bettless. Then the method was developed and refined in many works. The first works were the works of Pissanetzky on the magnetostatics and Kim on the magnetic field problems. The original Bettless formulation is based on and derived for the Laplace problems. This formulation is very similar to the finite element formulation except for the element domain. In this formulation infinite element domain extends toward infinity in one direction and the corresponding shape functions being non polynomial but integrable over the element. Subsequently, Infinite elements are directly applicable in the Finite element method. Similar to the Finite element method, the order of the approximation and the choice of shape functions directly relate to the accuracy of an infinite element.

The mapped infinite elements were developed by Bettess and Zienkiewicz. These elements allow using polynomial shape functions and the used technique generates shape functions which are consistent with the form of the solution of the exterior domain. A mathematically precise variational formulation of infinite elements has only recently been discussed.

\section{PRACTICAL CLASSIFICATION OF INFINITE ELEMENTS}

From practical point of view infinite element can be classified into five classes:

- classical infinite elements,

- decay infinite elements,

- mapped infinite elements,

- elastodynamical infinite elements and

- Wave envelope infinite elements. 
The origin of the idea and the development of every one of the above classes are difficult to be dated. The first class infinite elements are based on the original so called "classical" formulation of the infinite elements. Decay functions from different mathematical types are used in the decay infinite element formulation. The mapped infinite elements are developed by using mapping functions. These functions map the infinite domain of the element into a finite. By this approach the obtained infinite element is similar to the classical finite element. The latest researches of infinite elements are devoted to the development of the elestodynamical infinite elements and wave envelope infinite elements. The last two classes can be treated as a special combination of the mapped and decay infinite elements.

\section{MULTI-WAVE ELASTODYNAMICAL QUADRI- LATERAL FOUR NODE INFINITE ELEMENT}

The displacement field in the elastodynamical infinite element can be described in the standard form of the shape functions based on wave propagation functions [7] as:

$$
\mathbf{u}(x, z, \omega)=\sum_{i=1}^{n} \sum_{q=1}^{m} N_{i q}(x, z, \omega) \mathbf{p}_{i q}(\omega)
$$

or

$$
\mathbf{u}(x, z, \omega)=N_{p}(x, z, \omega) \mathbf{p}(\omega)
$$

where $N_{i q}(x, z, \omega)$ are the standard shape displacement functions, $\mathbf{p}_{i q}(\omega)$ is the generalized coordinates associated with $N_{i q}(x, z, \omega), n$ is the number of nodes for the element and $m$ is the number of wave functions included in the formulation of the infinite element. For horizontal wave propagation basic shape functions can be expressed as:

$$
N_{i q}(x, z, \omega)=L_{i}(\eta) W_{q}(\xi, \omega)
$$

where $W_{q}(\xi, \omega)$ are horizontal wave functions. By taking into account only the real parts of the wave functions, the equations of the wave propagation can be written as:

$\operatorname{Re} W_{q}(\xi, \omega)=\cos \left(\frac{i \omega}{c_{s}} \xi\right) e^{-\alpha \xi}$

or

$\operatorname{Re} W_{q}(\xi, \omega)=\cos \left(\frac{i \omega}{c_{p}} \xi\right) e^{-\alpha \xi}$

where $C_{S}, C_{p}$ are the velocities of the $S$-waves and $P$ waves respectively.

Expanding these functions in a Fourier-like series for all wave functions included in the formulation of the infinite element, the shape functions can be written as:
$\operatorname{Re} W(\xi, t)=\frac{1}{m} \sum_{q=1}^{m} A_{q} \cos \left(\frac{i \varpi q}{c_{s}} \xi\right) e^{-\alpha \xi}$

or

$\operatorname{Re} W(\xi, t)=\frac{1}{m} \sum_{q=1}^{m} A_{q} \cos \left(\frac{i \varpi q}{c_{s}} \xi\right) e^{-\alpha \xi}$

or

$\operatorname{Re} W(\xi)=\frac{1}{m} \sum_{q=1}^{m} A_{q} \cos \left(\frac{i \varpi q}{c_{s}} \xi\right) e^{-\alpha \xi}$

or

$\operatorname{Re} W(\xi)=\frac{1}{m} \sum_{q=1}^{m} A_{q} \cos \left(\frac{i \varpi q}{c_{p}} \xi\right) e^{-\alpha \xi}$

where $\boldsymbol{\sigma}$ is the lowest frequency and $\omega=\bar{\sigma} q$. The coefficients $A_{q}$ can be written as:

$$
A_{q}=\int_{0}^{T_{x}} \operatorname{Re} W(\xi, t) \cos \left(\frac{i \varpi q}{c_{s}} \xi\right) d t
$$

or in the form

$$
A_{q}=\frac{1}{\Omega_{e}} \int_{0}^{\Omega_{e}} \operatorname{Re} W(\xi, t) \cos \left(\frac{i \varpi q}{c_{s}} \xi\right) d t
$$

Using introduced in [11] hypotheses for the shape functions, equation (4) can be expressed as

$$
\operatorname{Re} W(\xi, t)=\frac{1}{m} \sum_{q=1}^{m} \sum_{n=1}^{\infty} 1 \cos \left(\frac{i \sigma q}{c_{s}} \xi\right) e^{-\alpha \xi}
$$

or

$$
\operatorname{Re} W(\xi, t)=\frac{1}{m} \sum_{q=1}^{m} \sum_{n=1}^{\infty} 1 \cos \left(\frac{i \varpi q}{c_{p}} \xi\right) e^{-\alpha \xi}
$$

and

$$
\operatorname{Re} W(\xi)=\frac{1}{m} \sum_{q=1}^{m} \sum_{n=1}^{\infty} 1 \cos \left(\frac{i \varpi q}{c_{s}} \xi\right) e^{-\alpha \xi}
$$

or

$$
\operatorname{Re} W(\xi)=\frac{1}{m} \sum_{q=1}^{m} \sum_{n=1}^{\infty} 1 \cos \left(\frac{i \omega q}{c_{p}} \xi\right) e^{-\alpha \xi}
$$

Then united shape function can be written as

$$
N_{i}(x, z, t)=\sum_{q=1}^{m} N_{i q}(x, z, \omega)=L_{i}(\eta) \operatorname{Re} W(\xi, t)
$$


$N_{i}(x, z)=\sum_{q=1}^{m} N_{i q}(x, z, \omega)=L_{i}(\eta) \operatorname{Re} W(\xi)$

and

$$
\begin{aligned}
& N_{i}(x, z, t) \mathbf{p}_{i}(t)=\sum_{q=1}^{m} N_{i q}(x, z, \omega) \mathbf{p}_{i q}(\omega)= \\
& =L_{i}(\eta) \operatorname{Re} W(\xi, t) \mathbf{p}_{i}(t)
\end{aligned}
$$

or

$$
\begin{aligned}
& N_{i}(x, z) \mathbf{p}_{i}=\sum_{q=1}^{m} N_{i q}(x, z, \omega) \mathbf{p}_{i q}(\omega)= \\
& =L_{i}(\eta) \operatorname{Re} W(\xi) \mathbf{p}_{i}
\end{aligned}
$$

and

Now equation (1) can be expressed as

$$
\mathbf{u}(x, z, t)=\sum_{i=1}^{n} N_{i}(x, z, t) \mathbf{p}_{i}(t)
$$

or

$$
\mathbf{u}(x, z)=N_{p}(x, z) \mathbf{p}
$$

In equation (4.a), (6.a), (7.a), (8.a) and (9.a) time $t$ is included indirectly.

The procedure described by the equations (4), (5) and (6) can be treated as superposing procedure based on a finite number of terms, where real components of the wave functions $\operatorname{Re} W_{q}(\xi, \omega)$ are preliminary shape functions or basis functions from mathematical point of view, and coefficients $A_{q}$ are generalized coordinates with only one component, corresponding to the node $i$ or weight coefficients from mathematical point of view.

It can be easily shown that in the case of only one wave function used in the computational model, only one frequency, the proposed multi-wave elastodynamical infinite element is reduced to single-wave elastodynamical infinite element. It can be treated as a special case. In this case

$$
N_{i}(x, z, t)=N_{i q}(x, z, \omega)=L_{i}(\eta) \operatorname{Re} W(\xi, \omega)_{(10)}
$$

or

$$
N_{i}(x, z)=N_{i q}(x, z)=L_{i}(\eta) \operatorname{Re} W(\xi)
$$

\section{TWO DIMENSIONAL MAPPED INFINITE ELEMENT}

Mapping functions and the Lagrangian isoparametric shape functions are given for a 2D axisymmetric four node quadrilateral mapping infinite element and for a 2D axisymmetric eight node quadrilateral mapping infinite element can be written as

\subsection{D axisymmetric four node quadrilateral mapping infinite element}

5.1.1 Mapping functions

$$
\begin{aligned}
& x=x_{I} \frac{(1-\eta)(-\xi)}{1-\xi}+x_{J} \frac{(1+\eta)(-\xi)}{1-\xi}+ \\
& +\frac{1}{2} x_{K} \frac{(1+\eta)(1+\xi)}{1-\xi}+\frac{1}{2} x_{L} \frac{(1-\eta)(1+\xi)}{1-\xi} \\
& y=y_{I} \frac{(1-\eta)(-\xi)}{1-\xi}+y_{J} \frac{(1+\eta)(-\xi)}{1-\xi}+ \\
& +\frac{1}{2} y_{K} \frac{(1+\eta)(1+\xi)}{1-\xi}+\frac{1}{2} y_{L} \frac{(1-\eta)(1+\xi)}{1-\xi}
\end{aligned}
$$

5.1.2 Lagrangian isoparametric shape functions

$$
\begin{aligned}
& u=\frac{1}{4} u_{I}(1-\eta)\left(\xi^{2}-\xi\right)+\frac{1}{4} u_{J}(1+\eta)\left(\xi^{2}-\xi\right)+ \\
& +\frac{1}{4} u_{K}(1+\eta)\left(1-\xi^{2}\right)+\frac{1}{4} u_{L}(1-\eta)\left(!-\xi^{2}\right)
\end{aligned}
$$

\subsection{D axisymmetric eight node quadrilateral mapping infinite element.}

5.2.1 Mapping functions

$$
\begin{aligned}
& x=x_{I} \frac{(1-\eta)(-1-\xi-\eta)}{1-\xi}+2 x_{J} \frac{\left(1-\eta^{2}\right)}{1-\xi}+ \\
& +x_{K} \frac{(1+\eta)(-1-\xi+\eta)}{1-\xi}+\frac{1}{2} x_{L} \frac{(1+\eta)(1+\xi)}{1-\xi}+ \\
& +\frac{1}{2} x_{M} \frac{(1+\eta)(1+\xi)}{1-\xi}
\end{aligned}
$$




$$
\begin{aligned}
& y=y_{I} \frac{(1-\eta)(-1-\xi-\eta)}{1-\xi}+2 y_{J} \frac{\left(1-\eta^{2}\right)}{1-\xi}+ \\
& +y_{K} \frac{(1+\eta)(-1-\xi+\eta)}{1-\xi}+\frac{1}{2} y_{L} \frac{(1+\eta)(1+\xi)}{1-\xi}+ \\
& +\frac{1}{2} y_{M} \frac{(1+\eta)(1+\xi)}{1-\xi}
\end{aligned}
$$

5.2.2 Lagrangian isoparametric shape functions

$$
\begin{aligned}
& u=\frac{1}{4} u_{l}(1-\eta)(1-\xi)(-1-\eta-\xi)+ \\
& +\frac{1}{2} u_{J}\left(1-\eta^{2}\right)(1-\xi)+ \\
& +\frac{1}{4} u_{K}(1+\eta)(1-\xi)(-1+\eta-\xi)+ \\
& +\frac{1}{2} u_{L}(1+\eta)\left(1-\xi^{2}\right)+\frac{1}{2} u_{M}(1-\eta)\left(1-\xi^{2}\right)
\end{aligned}
$$

\subsection{Mass and stiffness matrices}

The stiffness and mass matrices can be given in a standard of the Finite element method style as

$$
\left[k_{e}\right]=\int_{\Omega_{e}}[\bar{B}]^{T}[D][\bar{B}] d \Omega_{e}
$$

and

$$
\left[m_{e}\right]=\left(\int_{\Omega_{e}}[\bar{N}]^{T}[\bar{N}] d \Omega_{e}\right) I
$$

where $[N]$ are the shape functions and the $\left\{B_{i}\right\}$ vectors in the matrix $[B]$ are written as

$$
\left\{\bar{B}_{i}\right\}=\left\{\begin{array}{l}
\frac{\partial \bar{N}_{i}}{\partial x} \\
\frac{\partial \bar{N}_{i}}{\partial y}
\end{array}\right\} \quad \text { or } \quad\left\{\bar{B}_{i}\right\}=[J]^{1}\left\{\begin{array}{l}
\frac{\partial \bar{N}_{i}}{\partial \eta} \\
\frac{\partial \bar{N}_{i}}{\partial \xi}
\end{array}\right\}
$$

where $[J]^{1}$ is the Jacobian matrix which defines the geometrical mapping and can be written as

$$
[J]^{1}=\sum_{i=1}^{4}\left\{\begin{array}{ll}
\frac{\partial N_{i}}{\partial \eta} x_{i} & \frac{\partial N_{i}}{\partial \eta} y_{i} \\
\frac{\partial N_{i}}{\partial \xi} x_{i} & \frac{\partial N_{i}}{\partial \xi} y_{i}
\end{array}\right\}
$$

The domain differential $d \Omega_{e}$ must also be written in terms of the local coordinates as

$$
d \Omega_{e}=d x d y=[J] d \eta d \xi
$$

Subject to the evaluation of $\left\{B_{i}\right\}$ and $d \Omega_{e}$, which involves the mapping functions, the element stiffness and mass matrices may not be computed with standard Gaussian quadrature procedure. Note also that $u$ and $\bar{N}$ are shape functions but $N$ and $M$ are mapping functions.

\section{CONTINUITY THROUGH FINITE AND INFINITE ELEMENTS}

The continuity through finite and infinite elements can be enforced in exactly the same way as between two finite elements because they have same degrees of freedom and approximation polynomial degrees. A sketch of the boundary between finite and infinite elements is given in Fig.1

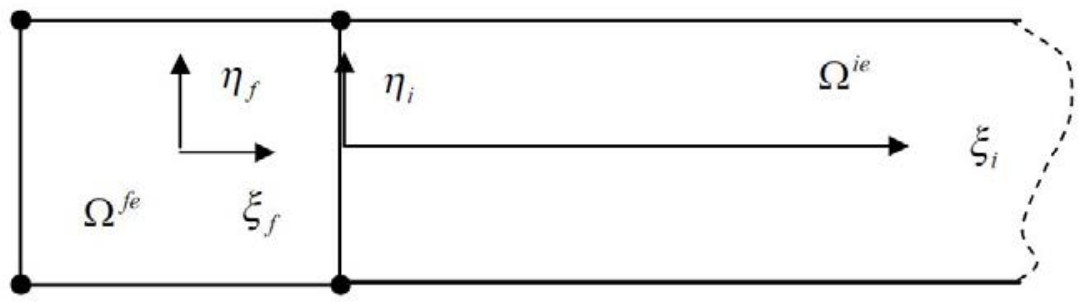

Fig. 1 Sketch of the boundary between finite and infinite elements 


\section{$7 C^{(n)}$ RATE OF CONTINUITY}

Here some basic requirements for $C^{(n)}$ continuity into the element domain and on the whole domain (the near and far field) are given.

$C^{(n)}$ continuity of a function $u_{e}(\xi, \eta)$ in a domain $\Omega_{e}$ is valid if

- The function $u_{e}(\xi, \eta)$ is of power $n+1$,

- The function $u_{e}(\xi, \eta)$ is $n$ times differentiable and the surface $u_{e}^{(n)}(\xi, \eta)$ is smooth.

- $C^{(n)}$ continuity of a function $u(x, y)$ in a domain $\Omega$ is valid if

- The function $u(x, y)$ is of power $n+1$,

- The function $u(x, y)$ is $n$ times differentiable and the surface $u^{(n)}(x, y)$ is smooth

- The function $u(x, y)$ is $n+1$ times differentiable on the nodes.

- Very often in SSI structural analysis it is enough to be ensured only $C_{1}$ continuity along finite element / infinite element (FE/IE) line or so-called artificial boundary in the form:

If line $\eta=$ const includes a node on the FE/IE line then

- The wave functions $W_{q}(\xi, \omega)$ and their first partial derivatives $\frac{\partial}{\partial \xi} W_{q}(\xi, \omega) \equiv W_{q}^{\xi}(\xi, \omega)$ have to be continuous and smooth on the line and also $W_{q}^{\xi}(\xi, \omega)=0$ is needed on the nodes

If line $\eta=$ const does not include a node on the $\mathrm{FE} / \mathrm{IE}$ line then

- The wave functions $W_{q}(\xi, \omega)$ and their first partial derivatives $\frac{\partial}{\partial \xi} W_{q}(\xi, \omega) \equiv W_{q}^{\xi}(\xi, \omega)$ have to be continuous and only the wave functions $W_{q}(\xi, \omega)$ have to be smooth. Also $W_{q}^{\xi}(\xi, \omega)=0$ on the finite side of the infinite element is needed.

Requirement $W_{q}^{\xi}(\xi, \omega)=0$ is needed on the every one point of the $\mathrm{FE} / \mathrm{IE}$ line, then

$$
\frac{\partial}{\partial \xi} N_{i q}(x, z, \omega)=L_{i}(\eta) \frac{\partial}{\partial \xi} W_{q}(\xi, \omega)
$$

When only the real parts of the wave functions are used

$\frac{\partial}{\partial \xi} \operatorname{Re} W_{q}(\xi, \omega)=\frac{\partial}{\partial \xi}\left(\cos \left(\frac{i \omega}{c_{s}} \xi\right) e^{-\alpha \xi}\right)$

or

$\frac{\partial}{\partial \xi} \operatorname{Re} W_{q}(\xi, \omega)=\frac{\partial}{\partial \xi}\left(\cos \left(\frac{i \omega}{c_{p}} \xi\right) e^{-\alpha \xi}\right)$

Global FE/IE line is identical with local infinite element line $\xi=0$, see figure 1. For $\xi=0$

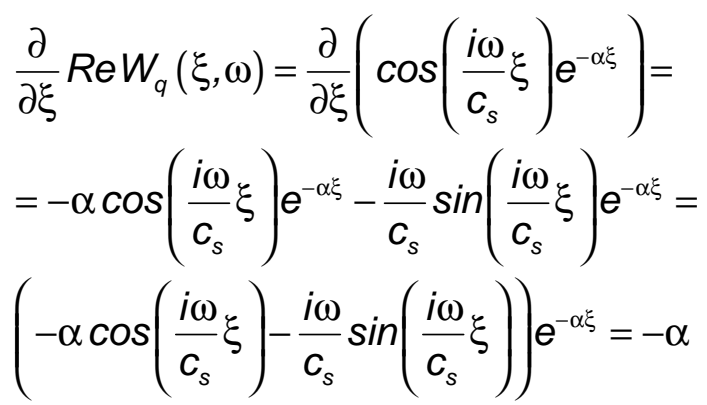

or

$\frac{\partial}{\partial \xi} \operatorname{Re} W_{q}(\xi, \omega)=\frac{\partial}{\partial \xi}\left(\cos \left(\frac{i \omega}{c_{p}} \xi\right) e^{-\alpha \xi}\right)=$
$=-\alpha \cos \left(\frac{i \omega}{c_{p}} \xi\right) e^{-\alpha \xi}-\frac{i \omega}{c_{p}} \sin \left(\frac{i \omega}{c_{p}} \xi\right) e^{-\alpha \xi}=$

$\left(-\alpha \cos \left(\frac{i \omega}{c_{p}} \xi\right)-\frac{i \omega}{c_{p}} \sin \left(\frac{i \omega}{c_{p}} \xi\right)\right) e^{-\alpha \xi}=-\alpha$

When we assume $\alpha \leq \delta$ we practically ensure the requirement.

For the functions written as (4) and (4.a) the above requirement can be expressed as

$\frac{\partial}{\partial \xi} \operatorname{Re} W(\xi, t)=\frac{1}{m} \sum_{q=1}^{m} A_{q} \frac{\partial}{\partial \xi} \cos \left(\frac{i \varpi q}{c_{s}} \xi\right) e^{-\alpha \xi}=-\alpha$

or

$\frac{\partial}{\partial \xi} \operatorname{Re} W(\xi, t)=\frac{1}{m} \sum_{q=1}^{m} A_{q} \frac{\partial}{\partial \xi} \cos \left(\frac{i \varpi q}{c_{p}} \xi\right) e^{-\alpha \xi}=-\alpha$

and

$\frac{\partial}{\partial \xi} \operatorname{Re} W(\xi)=\frac{1}{m} \sum_{q=1}^{m} A_{q} \frac{\partial}{\partial \xi} \cos \left(\frac{i \varpi q}{c_{s}} \xi\right) e^{-\alpha \xi}=-\alpha$

or

$\frac{\partial}{\partial \xi} \operatorname{Re} W(\xi)=\frac{1}{m} \sum_{q=1}^{m} A_{q} \frac{\partial}{\partial \xi} \cos \left(\frac{i \varpi q}{c_{p}} \xi\right) e^{-\alpha \xi}=-\alpha$ 


\section{CONCLUSION}

This paper deals with the mapping functions and the Lagrangian isoparametric shape functions for a 2D axisymmetric four node quadrilateral mapping infinite element and for a 2D axisymmetric eight node quadrilateral mapping infinite element. In addition, the basic aspects of the $C_{1}$ and the $C_{n}$ continuity along finite/infinite element line in two-dimensional substructure Soil-Structure Interaction problems are analyzed and discussed. In this class of models such a line marks artificial boundary between the near and the far field of the model. Finally, some important remarks about the $C_{1}$ and the $C_{n}$ continuity are reviewed when the author proposed using wave functions in SoilStructure Interaction models.

\section{EFERENCES}

[1] Wolf J.P, Song C, Finite-element modeling of unbounded media. Willey, 1996.

[2] Bathe K.J., Finite element procedures in engineering analysis. Prentice-Hill, 1982.

[3] Банков Б.П., Павлова Ю.В. "Метод на Крайните Елементи в строителната механика". София, УАСГ, 1996г.

[4] Ungless R.F., "Un infinite elements", M.A. Sc. Dissertation, University of British Columbia, 1973.

\section{ABSTRACT}

\section{ON A MULTI-WAVE ELASTODYNAMICAL QUADRILATERAL INFINITE ELEMENT FOR SOIL STRUCTURE INTERACTION}

\section{Konstantin S. KAZAKOV}

In this paper, a multi-wave elastodynamical quadrilateral infinite element is proposed. This kind of element is appropriate for multi-wave soil-structure interaction problem. The formulation is based on the standard steps which are the same as in the Finite element method after mapping the infinite to finite domain of the element. It is shown that in the case of only one wave function used in the formulation, only one frequency, the proposed multiwave elastodynamical infinite element is reduced as a special case to single-wave elastodynamical infinite element.

In addition, the mapping and the Lagrangian isoparametric shape functions for a $2 \mathrm{D}$ axisymmetric four node multi-wave elastodynamical quadrilateral infinite element and for a 2D axisymmetric eight node multi-wave elastodynamical quadrilateral infinite element are given. The basic aspects of the $C_{1}$ and the $C_{n}$ continuity along the finite/infinite element (artificial boundary) line in two-dimensional substructure SoilStructure Interaction problems are discussed. In this class of models such a line marks artificial boundary between the near and the far field of the model.

Key words: Wave propagation, Infinite Elements, Finite Element Method, Soil-Structure Interaction
[5] Bettess P., "Infinite elements", IJNME, 1978; 11:5464.

[6] Honjo Y., Pokharel G., "Parametric infinite elements for seepage analysis", IJNME, 1993; 17:45-66.

[7] Yan Ch. B., Kim D.K., Kim J.N., "Analytical frequency-dependent infinite elements for soil-structure interaction analysis in two-dimensional medium", Engineering Structures 22 (2000); 258-271.

[8] Wolf J.P., "Soil-Structure Interaction Analysis in Time Domain", Englewood Cliffs, N.J.: PrenticeHill, 1988.

[9] Kazakov K, "One model of one-dimensional wave propagation in homogeneous media" Stroitelstvo 6/2004, 12-14. (in Bulgarian)

[10] Kazakov K, "An adequate computational model of the infinite soil for Soil-Structure Interaction Problems", Proceedings of X Congress of applied mechanics, BAS, Varna, 2005.

[11] Kazakov K, "On the model of elastodynamical infinite element for the far field in Soil-Structure Interaction problems", Proceedings of National conference with international participation of VSU "Liuben Karavelov", 2005. (in Bulgarian).

[12] Kazakov K, "A model if FEM type elastodynamical infinite element for Soil-Structure Interaction", Proceedings of the 4-th International Conference on New trends in Static and Dynamics of structure 20-21 October 2005. Bratislava, Slovakia.

\section{REZIME}

\section{O MULTIVALNOM ELASTODINAMIČKOM KVADRILA- TERALNOM BESKONAČNOM ELEMENTU ZA OBUHVATANJE INTERAKCIJE KONSTRUKCIJE I TLA}

\section{Konstantin S. KAZAKOV}

U ovom radu predložen je višetalasni elastodinamički četvorougaoni beskonačni element. Ova vrsta elementa je pogodna za proučavanje problema višetalasne interakcije konstrukcija-tlo. Formulacija se zasniva na standardnim koracima koji su isti kao u metodi konačnih elemenata (MKE) nakon mapiranja beskonačnog $u$ konačni domen elementa. Pokazano je da se u slučaju samo jedne talasne funkcije (samo jedne frekvencije) koja se koristi u formulaciji, predloženi višetalasni elastodinamički beskonačni element svodi na poseban slučaj jednotalasnog elastodinamičkog beskonačnog elementa.

Pored toga, prikazani su preslikavanje i Lagranžove izoparametarske funkcije oblika za 2D osnosimetrični višetalasni elastodinamički četvorougaoni beskonačni element i za 2D osnosimetrični višetalasni elastodinamički četvorougaoni beskonačni element sa osam čvorova. Razmatraju se i osnovni aspekti $\mathrm{C}_{1}$ i $\mathrm{C}_{n}$, kontinuiteta duž pseudo-granične linije konačnog i beskonačnog elementa $u$ dvodimenzionalnom problemu interakcije konstrukcija-tlo. U ovoj klasi modela takva linija označava veštačku granicu između bliskog i udaljenog polja modela.

Ključne reči: prostiranje talasa, beskonačni elementi, metoda konačnih elemenata, interakcija konstrukcije i tla 